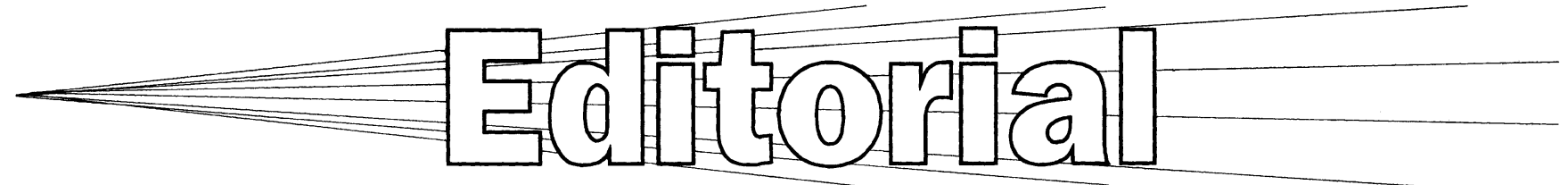

\title{
Journal Evolution
}

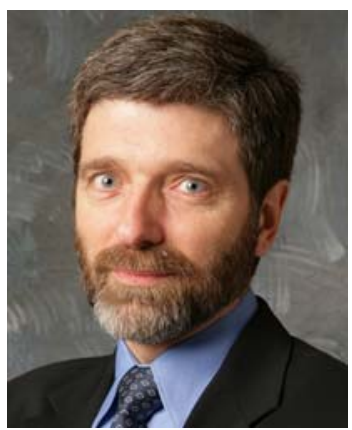

Christian Moreau

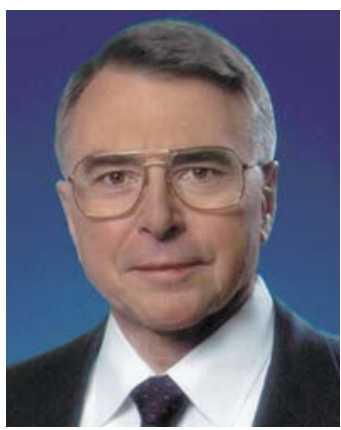

Robert C. Tucker, Jr.

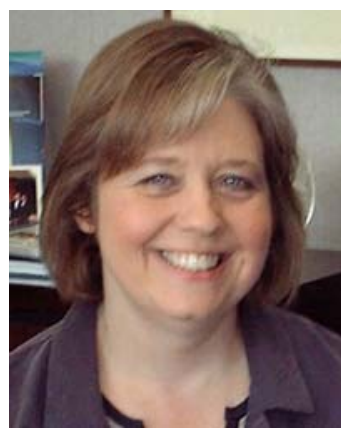

Mary Anne Fleming

The Journal of Thermal Spray Technology (JTST) is entering its 18th year and is still improving! With the transition to Springer as its publisher, the Journal now has approximately 2780 institutional subscribers. The general quality of its papers has continuously improved due to both its reputation as the leading journal in the field (thus attracting better papers) and its well developed peer review process (thus ensuring acceptance of only high quality papers). As a result, its impact factor has significantly improved over the years, which subsequently attracts more and better papers. To continue this progress, it has become advisable to consider the overall content of the Journal.

Beginning with the March 2009 issue, several sections will be removed from the Journal and be included in the International Thermal Spray \& Surface Engineering (iTSSe) publication, which is published as part of the thermal spray section of Advanced Materials \& Processes (AM\&P) magazine. The sections that will be moved include the Calendar of Events, In the News, Discussion Topics and Threads on Thermal Spray, Meet Our New Colleagues, and some editorials and commentaries. In addition to the peer reviewed papers, the sections retained in the Journal include Patents, Selected Abstracts, and Editorials and Commentaries that are written specifically for the Journal.

The changes will enhance the image of the Journal as a premier scientific and engineering journal, allow more focus on this community, and free more space in the Journal for peer reviewed papers. It will enable the Editors and ASM staff to concentrate all of their efforts on reviewing and processing manuscripts in a timely manner. Most important, the changes are in the best interests of the target audiences for the sections being moved. Springer is a large, efficient publisher whose markets are more scientific and R\&D than industrial. Conversely, AM\&P is widely distributed to the industrial community including all members of ASM International.

It is also worth noting that a growing fraction of the primary users of scientific and technical journals read or refer to papers by going directly to a specific paper electronically through the services of their library, without ever seeing any other material in the journal. Thus the visibility of news and similar features in the Journal is greatly reduced. The same information in iTSSe, however, would receive much greater attention from the readers of $A M \& P$.

As always, the JTST Editors, the Editorial Committee, and the staff are very interested in your comments, welcoming also criticisms or suggestions for improvement in any aspect of the Journal content or its publication processes. You can contact us at the e-mail addresses shown below.

Christian Moreau

Editor-in-Chief

e-mail: christian.moreau@cnrc-nrc.gc.ca

Robert C. Tucker, Jr.

Chair, Editorial Committee

e-mail: rctucker@aol.com

Mary Anne Fleming

Journals Manager, ASM International

e-mail: mary.anne.fleming@asminternational.org 